\title{
Time series decomposition into dyslipidemia prevalence among urban Chinese population: secular and seasonal trends
}

Jiahui Lao ${ }^{1,2,3}$, Yafei Liu ${ }^{1,2,3}$, Yang Yang ${ }^{1,2,3}$, Peng Peng ${ }^{4}$, Feifei Ma ${ }^{4}$, Shuang $\mathrm{Ji}^{4}$, Yujiao Chen ${ }^{4}$ and Fang Tang ${ }^{1,2,3^{*}}$

\begin{abstract}
Background: Previous epidemiological studies have indicated the seasonal variability of serum lipid levels. However, little research has explicitly examined the separate secular and seasonal trends of dyslipidemia. The present study aimed to identify secular and seasonal trends for the prevalence of dyslipidemia and the 4 clinical classifications among the urban Chinese population by time series decomposition.
\end{abstract}

Methods: A total of 306,335 participants with metabolic-related indicators from January 2011 to December 2017 were recruited based on routine health check-up systems. Multivariate direct standardization was used to eliminate uneven distributions of the age, sex, and BMI of participants over time. Seasonal and trend decomposition using LOESS (STL decomposition) was performed to break dyslipidemia prevalence down into trend component, seasonal component and remainder component.

Results: A total of $21.52 \%$ of participants were diagnosed with dyslipidemia, and significant differences in dyslipidemia and the 4 clinical classifications were observed by sex $(P<0.001)$. The secular trends of dyslipidemia prevalence fluctuated in 2011-2017 with the lowest point in September 2016. The dyslipidemia prevalence from January to March and May to July was higher than the annual average $(\lambda=1.00,1.16,1.06,1.01,1.02,1.03)$, with the highest point in February. Different seasonal trends were observed among the 4 clinical classifications. Compared to females, a higher point was observed among males in February, which was similar to participants aged $<55$ years (vs. $\geq 55$ years) and participants with a BMI $\leq 23.9$ (vs. BMI > 23.9).

Conclusions: There were significant secular and seasonal features for dyslipidemia prevalence among the urban Chinese population. Different seasonal trends were found in the 4 clinical classifications of dyslipidemia. Precautionary measures should be implemented to control elevated dyslipidemia prevalence in specific seasons, especially in the winter and during traditional holidays.

\footnotetext{
* Correspondence: tangfangsdu@gmail.com

'Department of Endocrinology and Metabology, The First Affiliated Hospital of Shandong First Medical University \& Shandong Provincial Qianfoshan Hospital, Jinan, China

${ }^{2}$ Center for Big Data Research in Health and Medicine, The First Affiliated Hospital of Shandong First Medical University \& Shandong Provincial Qianfoshan Hospital, Jingshi Road 16766250014 Jinan, China

Full list of author information is available at the end of the article
}

(c) The Author(s). 2021 Open Access This article is licensed under a Creative Commons Attribution 4.0 International License, which permits use, sharing, adaptation, distribution and reproduction in any medium or format, as long as you give appropriate credit to the original author(s) and the source, provide a link to the Creative Commons licence, and indicate if changes were made. The images or other third party material in this article are included in the article's Creative Commons licence, unless indicated otherwise in a credit line to the material. If material is not included in the article's Creative Commons licence and your intended use is not permitted by statutory regulation or exceeds the permitted use, you will need to obtain permission directly from the copyright holder. To view a copy of this licence, visit http://creativecommons.org/licenses/by/4.0/ The Creative Commons Public Domain Dedication waiver (http://creativecommons.org/publicdomain/zero/1.0/) applies to the data made available in this article, unless otherwise stated in a credit line to the data. 
Keywords: Dyslipidemia, Time series decomposition, Secular trends, Seasonal trends, Hypercholesterolemia, Hypertriglyceridemia, Mixed hyperlipidemia, HDL-C hypolipidemia

\section{Background}

Dyslipidemia is characterized by increased total cholesterol (TC), low-density lipoprotein cholesterol (LDL-C), and triglyceride (TG) levels and/or reduced high-density lipoprotein cholesterol (HDL-C) levels [1]. Previous studies have shown that dyslipidemia could increase the risk of cardiac-cerebral vascular diseases, such as coronary artery disease (CAD) and stroke [2, 3]. Dyslipidemia causes over $50 \%$ of the CAD patients worldwide [4]. In China, the prevalence of dyslipidemia of adults is approximately $34.0 \%$ [5]. With the urbanization and improvement of the Chinese population's quality of life, the Chinese dyslipidemia prevalence is constantly increasing, especially in urban areas [6,7].

Epidemiological research has found seasonal variability of serum lipid and cardiac-cerebral vascular diseases. Previous studies suggested that TC levels were higher in cold seasons than hot seasons [8]. Peaks in winter were also found among cardiovascular diseases [9]. Considering the well-known relationship between serum lipid levels and cardiac-cerebral vascular diseases, seasonal variability in serum lipid levels might result in different incidences of cardiac-cerebral vascular diseases among seasons.

Abnormal serum lipid levels cause increased hazards of CAD and other cardiac-cerebral vascular diseases [10, 11]. The identification of seasonal trends of dyslipidemia prevalence is crucial to the prevention and control of related diseases. A few studies based on time series have explored seasonal trends of dyslipidemia [12]. To our knowledge, no study has separated secular trends and remainder from seasonal trends of dyslipidemia, which might help clarify seasonal variations in dyslipidemia prevalence. Moreover, most of the studies did not have sufficiently long research periods or sufficient participants. Therefore, the present study, based on the routine health check-up system, collected large-scale urban population health information which minimized potential recall and response biases [13], and first aimed to identify secular and seasonal trends of dyslipidemia prevalence among urban Chinese adults by time-series decomposition and then assess the different trends for the 4 clinical classifications and subgroups.

\section{Materials and methods}

\section{Participants}

This study included 306,335 participants aged 20 years or older who were attending routine health check-up program at the Center for Health Management of
Shandong Provincial Qianfoshan Hospital with serum lipids measurements from January 2011 to December 2017.

Eligible participants were (1) aged $\geq 20$ years and (2) with health records for TC, TG, HDL-C and LDL-C measurements, and age, sex, and body mass index (BMI) information. Participants were excluded if they had no exact check-up time that was recorded.

\section{Measurements}

According to the standard clinical and laboratory protocol, serum lipid levels were measured by the Roche Cobase c701 testing system. TC and TG were measured by enzyme colorimetry. HDL-C and LDL-C were measured by the direct catalase scavenging method and selective clearance method, respectively.

\section{Definition of dyslipidemia}

Based on the "2016 Chinese guidelines for the management of dyslipidemia in adults" [14], people will be diagnosed with dyslipidemia when: TC $\geq 6.2 \mathrm{mmol} / \mathrm{L}$ $(240 \mathrm{mg} / \mathrm{dl})$ or $\mathrm{TG} \geq 2.3 \mathrm{mmol} / \mathrm{L}(200 \mathrm{mg} / \mathrm{dl})$ or HDL$\mathrm{C}<1.0 \mathrm{mmol} / \mathrm{L} \quad(40 \mathrm{mg} / \mathrm{dl})$ or $\mathrm{LDL}-\mathrm{C} \geq 4.1 \mathrm{mmol} / \mathrm{L}$ $(160 \mathrm{mg} / \mathrm{dl})$. Dyslipidemia was further classified into 4 clinical classifications [14]: hypercholesterolemia $(\mathrm{TC} \geq$ $6.2 \mathrm{mmol} / \mathrm{L}$ or $240 \mathrm{mg} / \mathrm{dl}$ ), hypertriglyceridemia $(\mathrm{TG} \geq$ $2.3 \mathrm{mmol} / \mathrm{L}$ or $200 \mathrm{mg} / \mathrm{dl}$ ), mixed hyperlipidemia $(\mathrm{TC} \geq$ $6.2 \mathrm{mmol} / \mathrm{L}$ or $240 \mathrm{mg} / \mathrm{dl}$ and $\mathrm{TG} \geq 2.3 \mathrm{mmol} / \mathrm{L}$ or $200 \mathrm{mg} / \mathrm{dl}$ ), HDL-C hypolipidemia (HDL-C $<1.0 \mathrm{mmol} /$ $\mathrm{L}$ or $40 \mathrm{mg} / \mathrm{dl})$.

\section{Statistical analysis}

Before time series decomposition, chi-square tests were performed to analyze the difference in the prevalence of dyslipidemia and the 4 clinical classifications between males and females.

Considering the influence of age, sex, and BMI on dyslipidemia and uneven distribution of age, sex, and BMI of participants over time, adjusted prevalence was calculated by multivariate direct standardization, using the participants in the year 2011 of this study as the standard population.

The method of direct standardization was used as shown below:

$$
p^{\prime}=\frac{\sum N_{\mathrm{i}} p_{\mathrm{i}}}{N}
$$

where $p^{\prime}$ is the standardized prevalence, $N_{\mathrm{i}}$ is the number of standard populations of each group, $p_{\mathrm{i}}$ is the un- 
standardized prevalence of each group, and $N$ is the total number of standard populations.

A time series can be broken down into trend-cycle component (also called "trend", $T_{\mathrm{t}}$ ), seasonal component $\left(S_{\mathrm{t}}\right)$ and remainder component $\left(R_{\mathrm{t}}\right)$ [15]. In additive decomposition, the equation is $y_{\mathrm{t}}=S_{\mathrm{t}}+T_{\mathrm{t}}+R_{\mathrm{t}}$. In the equation, $y_{\mathrm{t}}$ is the time series data. Similarly, a multiplicative decomposition is $y_{\mathrm{t}}=S_{\mathrm{t}} * \mathrm{~T}_{\mathrm{t}} * \mathrm{R}_{\mathrm{t}}$.

After calculating the adjusted dyslipidemia prevalence for each month, the method of seasonal and trend decomposition using LOESS (STL decomposition) was used to break the prevalence down into trend component, seasonal component and remainder component [16]. LOESS (locally weighted regression) is a nonparametric method for local regression analysis for estimating nonlinear relationships. Inner loop and outer loop are included in the process of STL decomposition. The inner loop was used for trend fitting and cycle component calculation. The outer loop was used to regulate the robustness weight. Compared with classical decomposition methods, STL decomposition is more robust in reducing the effect of unusual observations on the estimates of the trend and seasonal components.

STL decomposition only provides facilities for additive decompositions. However, multiplicative decomposition was more appropriate for dyslipidemia prevalence in this study. Therefore, logarithmic transformation was conducted on the time series before STL decomposition. After decomposition, an exponential transformation was applied for the trend component, seasonal component and remainder component. When $\lambda$ of the seasonal trends was greater than 1 , it meant that the prevalence was higher than the annual average.

Subgroup analysis was performed by the same methods described above to identify the different secular and seasonal trends between participants of different characteristics.

Although multiplicative decomposition was considered more appropriate in this study, there was no definite quantitative determining criterion between the usage of multiplicative and additive decomposition. Therefore, sensitivity analysis was conducted for dyslipidemia prevalence by using STL decomposition without logarithmic transformation and exponential transformation, which is an additive decomposition approach.

$\mathrm{R}$ software (version 3.3.1) was used to conduct data analysis. The "stl()" function was used to develop STL decomposition. The level of statistical significance was 0.05 (two-sided).

\section{Results}

\section{Distribution and prevalence}

In total, 306,335 participants were included in the present study, comprising 185,490 males (accounting for $60.55 \%$, mean age $=46.2$, standard deviation $(S D)=14.5$ ) and 120,845 females (accounting for $39.45 \%$, mean age = $44.8, \mathrm{SD}=13.9)$. A total of $21.52 \%$ of participants were diagnosed with dyslipidemia. The prevalence was $26.05 \%$ for males and $14.58 \%$ for females. From 2011 to 2017, the dyslipidemia prevalence of all participants, males, and females was highest in 2013 and equal to $25.84 \%, 30.67 \%$, and $17.59 \%$, respectively.

As shown in Table 1, males had a higher prevalence of dyslipidemia, hypertriglyceridemia, mixed hyperlipidemia and HDL-C hypolipidemia than females, but a lower hypercholesterolemia prevalence than females (all $P<$ 0.001).

\section{Secular and seasonal trends of dyslipidemia prevalence}

In Fig. 1(A), significant seasonal variation in dyslipidemia prevalence was observed in the time series during 2011-2017. In Fig. 1(B), the secular trends of dyslipidemia prevalence fluctuated in 2011-2017 with the lowest point in September 2016. A continuous rising trend was observed from September 2016 to December 2017. Figure1(C) shows the seasonal trends of dyslipidemia prevalence over the course of a year. The prevalence from January to March and May to July was above the annual average and $\lambda$ was equal to $1.00,1.16,1.06,1.01,1.02$, and 1.03. The highest point was observed in February. Figure 1 (D) presents the time series of the remainder of the STL decomposition. Decomposition effects were further assessed by auto-correlation function (ACF) and partial auto-correlation function (PACF) of the remainder. The ACF and PACF of the remainder converged rapidly after 1-month lag (Supplemental Fig. 1). This demonstrated that there was no apparent autocorrelation of the remainder. The Ljung-Box test showed that the time series of the remainder was a white noise series (Ljung-Box test statistic $=0.720, P=0.997$ ). Therefore, time series decomposition in this study achieved a good effect.

\section{Secular and seasonal trends for the clinical classifications of dyslipidemia}

In Fig. 2, different secular trends were shown for the 4 clinical classifications. From the middle of 2016 to the end of 2017, a rising trend was observed for the prevalence of hypertriglyceridemia and hypercholesterolemia. A rising trend was also observed for HDL-C hypolipidemia during the second half of 2017.

Figure 3 presents the seasonal trends of the 4 clinical classifications. The prevalence of hypercholesterolemia and mixed hyperlipidemia was lower in June to August and higher at the beginning and end of the year. However, the prevalence of HDL-C hypolipidemia showed an increasing trend in spring and summer and a decreasing trend in autumn and winter. The peak hypertriglyceridemia prevalence occurred in July. 
Table 1 Prevalence of dyslipidemia and 4 clinical classifications during 2011-2017

\begin{tabular}{|c|c|c|c|c|c|}
\hline Clinical classification & All (\%) & Males (\%) & Females (\%) & $x^{2}$ & $P$ \\
\hline Dyslipidemia & 21.52 & 26.05 & 14.58 & 3757.23 & $<0.001$ \\
\hline Hypercholesterolemia & 7.06 & 6.24 & 8.32 & 416.09 & $<0.001$ \\
\hline Hypertriglyceridemia & 11.43 & 15.28 & 5.53 & 5573.25 & $<0.001$ \\
\hline HDL-C hypolipidemia & 6.38 & 9.12 & 2.17 & 5280.69 & $<0.001$ \\
\hline Mixed hyperlipidemia & 1.81 & 2.09 & 1.36 & 212.15 & $<0.001$ \\
\hline
\end{tabular}

\section{Results of subgroup analysis of dyslipidemia prevalence} by sex, age and BM

Figure 4 presents the secular and seasonal trends by STL decomposition in each subgroup. All secular trends of dyslipidemia prevalence among the six subgroups fluctuated in 20112017 with a continuous increasing trend from the middle of 2016 to December 2017. Compared to females, a higher point was observed among males in February. Similar trends were also observed among participants aged $<55$ years (vs. $\geq 55$ years) and participants with $\mathrm{BMI} \leq 23.9$ (vs. BMI > 23.9).

\section{Results of sensitivity analysis}

In STL decomposition without logarithmic transformation and exponential transformation (additive decomposition), secular and seasonal trends of dyslipidemia prevalence slightly changed but were still in line with multiplicative decomposition (Supplemental Fig. 2). The prevalence in January to March and May to July was also higher than the annual average. This result suggested that the results of this study were robust.

\section{Discussion}

This study collected data from a large sample of an urban Chinese population and found that $21.52 \%$ of participants were diagnosed with dyslipidemia and significant secular and seasonal features for dyslipidemia prevalence were observed. Different seasonal trends were also found in the 4 clinical classifications of

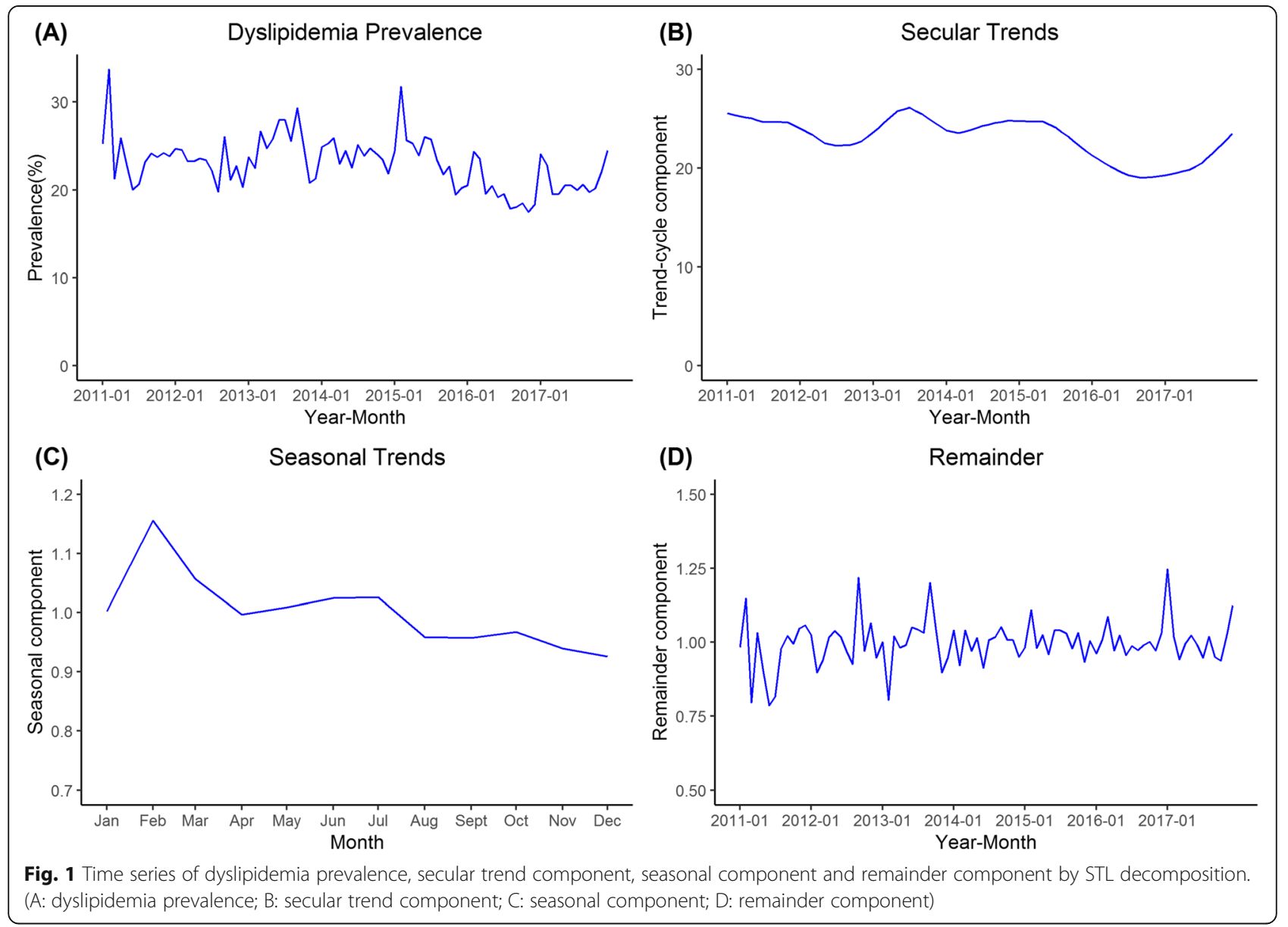



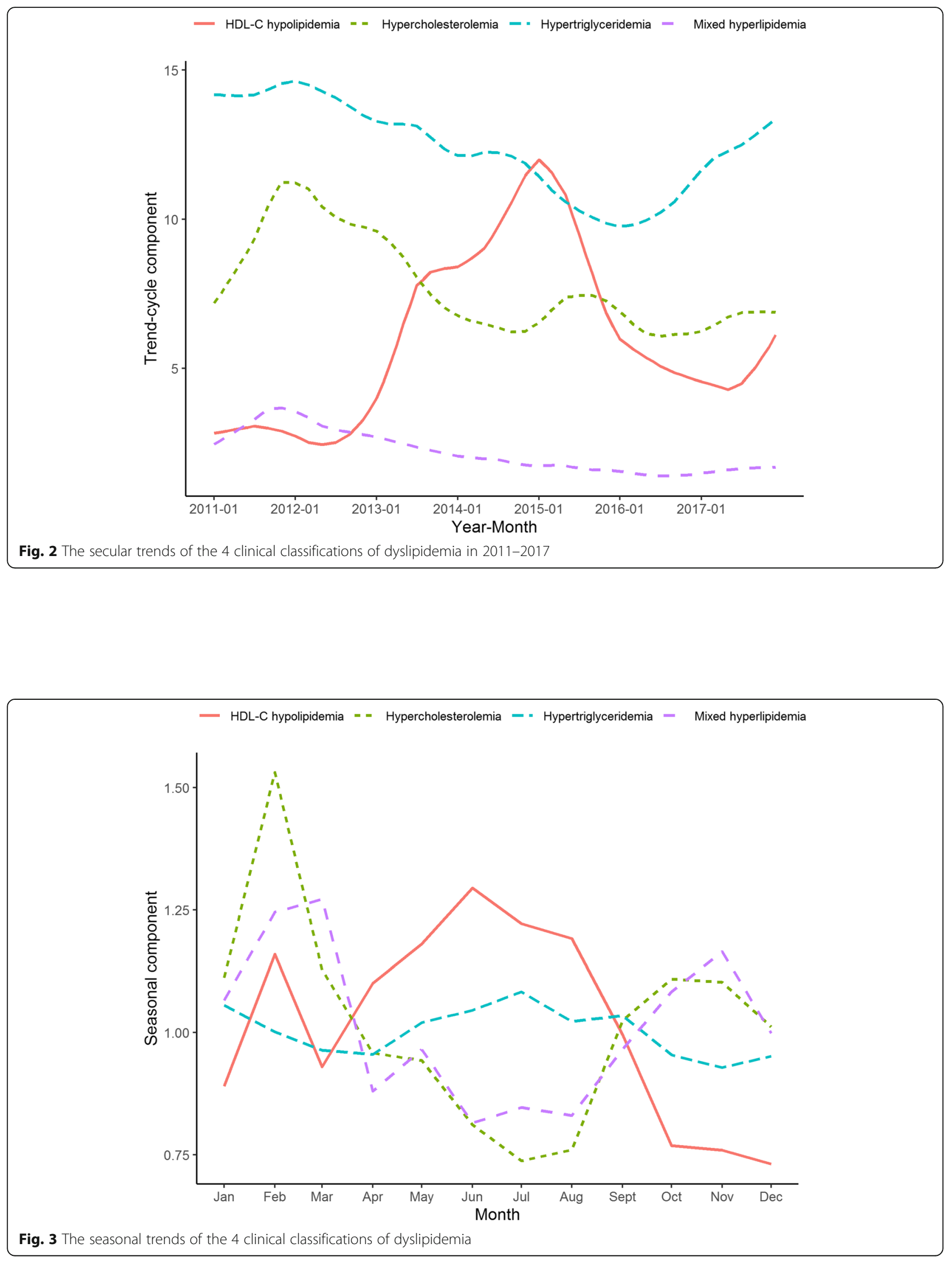


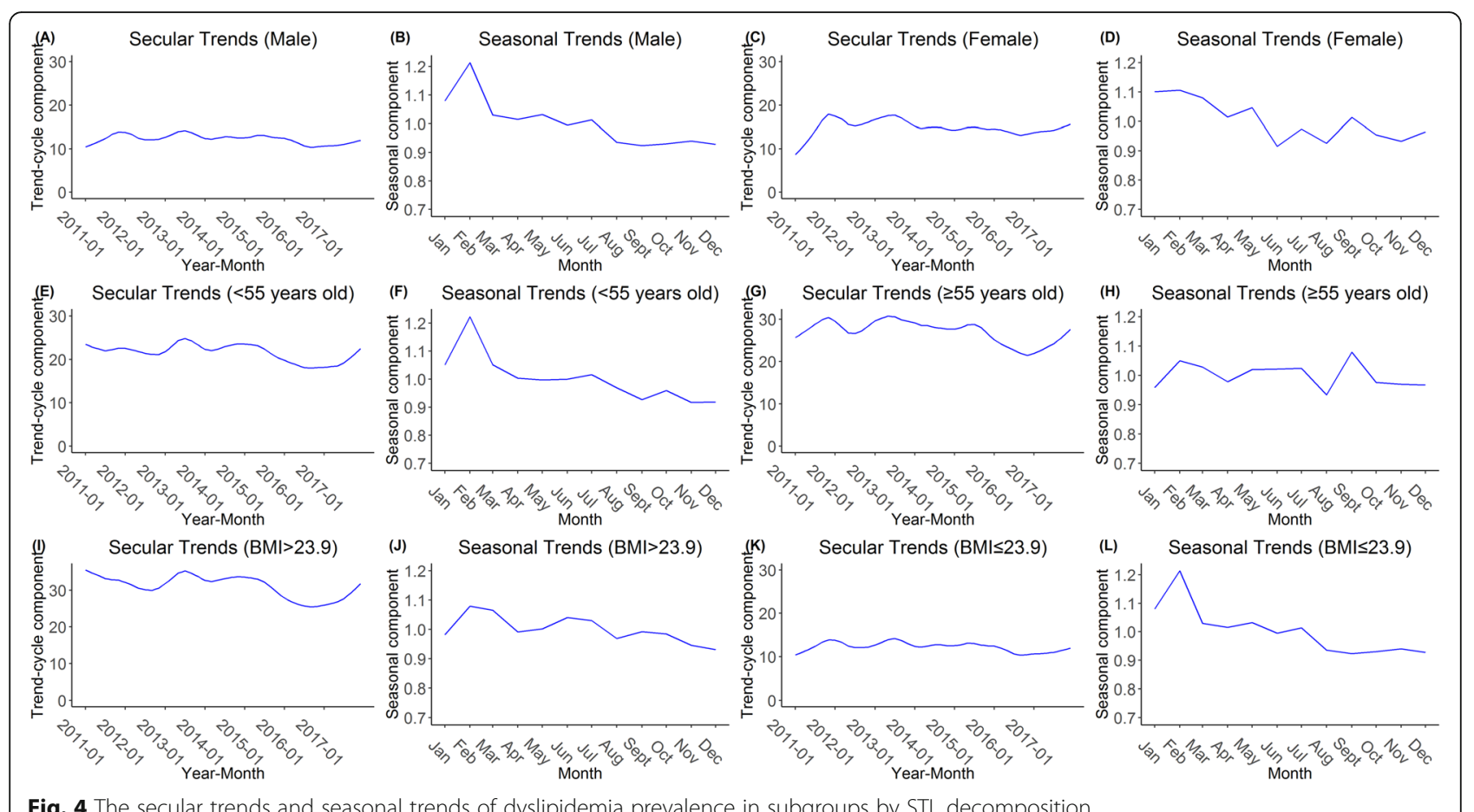

Fig. 4 The secular trends and seasonal trends of dyslipidemia prevalence in subgroups by STL decomposition

dyslipidemia. To our knowledge, this was the first study to explore secular and seasonal trends of dyslipidemia prevalence by STL time series decomposition. Compared with traditional methods, this approach provided a clearer understanding of secular and seasonal trends, which might be a significant supplement to the study of dyslipidemia seasonality.

The finding of the prevalence of dyslipidemia was similar to a previous study for adults of 18-69 years old in Shandong Province in 2011 (22.70\%) [17]. However, the result was lower than that of a previous study in nine provinces of China in 2011, which suggested that the dyslipidemia prevalence in adults was $39.91 \%$ [18]. The same phenomenon was observed in the prevalence of hypercholesterolemia ( $7.06 \%$ vs. $9.01 \%)$ and hypertriglyceridemia ( $11.43 \%$ vs. $27.02 \%)$. The reason for this result might be the different dietary patterns between Shandong and other provinces. Given that Shandong is a developed eastern coastal province in China, the residents in Shandong eat more meat that is rich in saturated fat and seafood [19]. Moreover, dyslipidemia was a serious public health problem in China and globally, and it was a strong risk factor for coronary artery diseases $[20,21]$. Early intervention of dyslipidemia will contribute to preventing coronary heart disease and improving the prognosis.

The seasonal trends of dyslipidemia prevalence or serum lipid level had been reported in previous studies. Studies in the UK, Japan, and Brazil obtained similar findings to this study about different levels of serum lipids in the summer and winter [22, 23]. However, it was different from those reported in the Helsinki heart study, which showed a drop in HDL-C levels (not HDL$C$ hypolipidemia prevalence) during mid-winter [24]. The differences in participants' genetic background, latitude and climate may be the reason for the different results.

For the clinical classifications, the seasonal pattern of hypercholesterolemia and mixed hyperlipidemia showed a decreasing trend from June to August and an increasing trend in the beginning and end of the year. This result was supported by a previous study, which suggested that temperature was an important influencing factor for serum lipids and the decreased air temperature could cause increased plasma lipid levels [25]. Exposure to cold outdoor temperatures increased the basic metabolism, improved the brown adipose tissue activity, and increased serum lipid levels [26]. A peak of hypertriglyceridemia prevalence was found in the summer, which was similar to a study in Poland [26]. A possible explanation is that increased alcohol intake in the summer could increase TG levels [27]. Evidence in previous research suggested that, due to the hot weather, summer was a high season of beer consumption in China [28].

The present study also indicated that the prevalence of dyslipidemia and hypercholesterolemia peaked in February. Generally, the Chinese population observes the most solemn and widely celebrated Spring Festival in February. During the Spring Festival, people like to stay at 
home and have dinner with family and friends. This may last for one or two weeks. Rich foods and lack of physical exercise for a relatively long time may lead to an increased prevalence of dyslipidemia [29].

\section{Study strengths and limitations}

One advantage of this study is that a large sample size with a relatively long study period was used to explore the secular and seasonal trends of dyslipidemia prevalence. Moreover, a stable and novel time series decomposition method, STL decomposition, was used to separate the secular trend and remainder from the seasonal trend of dyslipidemia.

The limitation of this study must be acknowledged. Despite controlling for the influence of age, sex, and BMI on dyslipidemia prevalence, some influencing factors of dyslipidemia (e.g., lifestyle, diet) were not collected. Secondly, this study is limited to the urban Chinese check-up population included in the routine health check-up system, of which some characteristics were different from those of the general population, rural residents, and people from other countries, which lead to a limited extension of the results to other populations.

\section{Conclusions}

The findings of this study indicated that, after time series decomposition, there were obvious seasonal features for dyslipidemia prevalence. Different seasonal trends were shown in 4 clinical classifications of dyslipidemia. Precautionary measures should be implemented to control the seasonal risks of dyslipidemia. A healthier diet and adequate exercise are needed in specific seasons (e.g., winter) and during holidays. In clinical practice, more seasonal-related guidance should be provided to patients suffering from dyslipidemia or cardiovascular and cerebrovascular diseases. Future research should focus on the mechanism of seasonal or meteorological factors on dyslipidemia and the 4 clinical classifications, including molecular biological mechanisms and changes in behaviors.

\section{Abbreviations}

TC: Total cholesterol; TG: Triglyceride; HDL-C: High-density lipoprotein cholesterol; LDL-C: Low-density lipoprotein cholesterol; BMI: Body mass index; STL: Seasonal and trend decomposition using LOESS; CAD: Coronary artery disease; SD: Standard deviation; ACF: Auto-correlation function; PACF: Partial auto-correlation function

\section{Supplementary Information}

The online version contains supplementary material available at https://doi. org/10.1186/s12944-021-01541-6.

Additional file 1.

\section{Acknowledgements}

We thank Institute for Medical Dataology, Shandong University for the assistance of data collection.

\section{Author contributions}

$\mathrm{FT}$ and $\mathrm{JL}$ designed the study. $Y \mathrm{~L}$ and $Y Y$ collected data of the study. $J \mathrm{~L}$ and YL analyzed the data. JL wrote the manuscript. TF, FM, PP, SJ and YC performed editing and revision to the manuscript. All authors approved the final version.

\section{Funding}

This study was funded by National Natural Science Foundation of China (71804093), Academic Promotion Programme of Shandong First Medical University (2019LJ005), Shandong Provincial Key Research and Development Program (Grant No. 2020RKB14114), and Shandong Provincial Medical and Health Science and Technology Development Project (SQ20170087).

\section{Availability of data and materials}

The data used in the present study are available from the corresponding author on reasonable request.

\section{Declarations}

Ethics approval and consent to participate

The study was approved by the Ethics Committee of Shandong Provincial Qianfoshan Hospital (No. for IRB approval: [2018] S0056). Written informed consent was obtained from all participants.

\section{Consent for publication}

Not applicable.

\section{Competing interests}

The authors declare that they have no competing interests in this paper.

\section{Author details}

${ }^{1}$ Department of Endocrinology and Metabology, The First Affiliated Hospital of Shandong First Medical University \& Shandong Provincial Qianfoshan Hospital, Jinan, China. ${ }^{2}$ Center for Big Data Research in Health and Medicine, The First Affiliated Hospital of Shandong First Medical University \& Shandong Provincial Qianfoshan Hospital, Jingshi Road 16766250014 Jinan, China. ${ }^{3}$ Shandong Provincial Qianfoshan Hospital, Cheeloo College of Medicine, Shandong University, Jinan, China. ${ }^{4}$ School of Public Health, Weifang Medical University, Weifang, China.

Received: 9 July 2021 Accepted: 2 September 2021

Published online: 22 September 2021

\section{References}

1. Bayram F, Kocer D, Gundogan K, Kaya A, Demir O, Coskun R, et al. Prevalence of dyslipidemia and associated risk factors in Turkish adults. J Clin Lipidol. 2014;8:206-16. https://doi.org/10.1016/j.jacl.2013.12.011.

2. Kopin L, Lowenstein C. Dyslipidemia. Ann Intern Med. 2017;167:ITC81-95. https://doi.org/10.7326/AITC201712050.

3. Aradine E, Hou Y, Cronin C, Chaturvedi S. Current Status of Dyslipidemia Treatment for Stroke Prevention. Curr Neurol Neurosci Rep. 2020;20:31. https://doi.org/10.1007/s11910-020-01052-4.

4. Liu HH, Li JJ. Aging and dyslipidemia: A review of potential mechanisms. Ageing Res Rev. 2015;19:43-52. https://doi.org/10.1016/j.arr.2014.12.001.

5. Pan L, Yang Z, Wu Y, Yin RX, Liao Y, Wang J, et al. The prevalence, awareness, treatment and control of dyslipidemia among adults in China. Atherosclerosis. 2016;248:2-9. https://doi.org/10.1016/j.atherosclerosis.2016. 02.006.

6. Xing $L$, Jing $L$, Tian $Y$, Yan $H$, Zhang B, Sun $Q$, et al Epidemiology of dyslipidemia and associated cardiovascular risk factors in northeast China: $A$ cross-sectional study. Nutrition, metabolism, and cardiovascular diseases. 2020; 30:2262-2270. https://doi.org/10.1016/j.numecd.2020.07.032.

7. Zhang M, Deng Q, Wang L, Huang Z, Zhou M, Li Y, et al. Prevalence of dyslipidemia and achievement of low-density lipoprotein cholesterol targets in Chinese adults: A nationally representative survey of 163,641 adults. Int J Cardiol. 2018;260:196-203. https://doi.org/10.1016/j.ijcard.2017.12.069. 
8. Ockene IS, Chiriboga DE, Stanek EJ, Harmatz MG, Nicolosi R, Saperia G, et al. Seasonal variation in serum cholesterol levels - Treatment implications and possible mechanisms. Arch Intern Med. 2004;164:863-70. https://doi.org/1 0.1001/archinte.164.8.863

9. Manfredini R, Fabbian F, Pala M, Tiseo R, De Giorgi A, Manfredini F, et al. Seasonal and Weekly Patterns of Occurrence of Acute Cardiovascular Diseases: Does a Gender Difference Exist? J Womens Health. 2011;20:16638. https://doi.org/10.1089/jwh.2011.2734.

10. Miller M, Stone NJ, Ballantyne C, Bittner V, Criqui MH, Ginsberg HN, et al. Triglycerides and Cardiovascular Disease A Scientific Statement From the American Heart Association. Circulation. 2011;123:2292-333. https://doi. org/10.1161/CIR.0b013e3182160726.

11. Gotto AM, Brinton EA. Assessing low levels of high-density lipoprotein cholesterol as a risk factor in coronary heart disease - A working group report and update. J Am Coll Cardiol. 2004;43:717-24. https://doi.org/10.101 6/j.jacc.2003.08.061.

12. Gordon D, Hyde J, Trost D, Whaley F, Hannan P, Jacobs D, et al. Cyclic Seasonal-Variation in Plasma-Lipid and Lipoprotein Levels - the Lipid Research Clinics Coronary Primary Prevention Trial Placebo Group. J Clin Epidemiol. 1988;41:679-89. https://doi.org/10.1016/ 0895-4356(88)90120-5.

13. Coughlin S. Recall bias in epidemiologic studies. J Clin Epidemiol. 1990;43: 87-91. https://doi.org/10.1016/0895-4356(90)90060-3.

14. Zhu JR, Gao RL, Zhao SP, Lu GP, Zhao D, Li JJ. 2016 Chinese guidelines for the management of dyslipidemia in adults Joint committee for guideline revision. J Geriatr Cardiol. 2018; 15:1-29. https://doi.org/10.11909/j.issn.16715411.2018.01.011.

15. Rob J, Hyndman G, Athanasopoulos. Forecasting: Principles and Practice. London: Bowker-Saur. Pharo; 2014. https://otexts.com/fpp2/.

16. Hafen RP, Anderson DE, Cleveland WS, Maciejewski R, Ebert DS, Abusalah A, et al. Syndromic surveillance: STL for modeling, visualizing, and monitoring disease counts. Bmc Med Inform Decis Mak. 2009;9:21. https://doi.org/10.11 86/1472-6947-9-21.

17. Zhang JY, Tang JL, Guo XL. [Prevalence of dyslipidemia among residents aged 18-69 years in Shandong province of China, 2011]. Chin J Prev Med. 2016:50:230-4

18. Dai J, Min JQ, Yang YJ. [A study on the epidemic characteristics of dyslipidemia in adults of nine provinces of China]. Zhonghua Xin Xue Guan Bing Za Zhi. 2018;46:114-8. https://doi.org/10.3760/cma.j.issn.0253-3758.201 8.02.009.

19. Lin LY, Hsu CY, Lee HA, Wang WH, Kurniawan AL, Chao JCJ. Dietary Patterns in Relation to Components of Dyslipidemia and Fasting Plasma Glucose in Adults with Dyslipidemia and Elevated Fasting Plasma Glucose in Taiwan. Nutrients. 2019;11:845. https://doi.org/10.3390/nu11040845.

20. Valgimigli M, Gragnano F, Branca M, Franzone A, Baber U, Jang Y, et al. P2Y12 inhibitor monotherapy or dual antiplatelet therapy after coronary revascularisation: individual patient level meta-analysis of randomised controlled trials. BMJ. 2021;373:n1332. https://doi.org/10.1136/bmj.n1332.

21. Calabrò P, Gragnano F, Di Maio M, Patti G, Antonucci E, Cirillo P, et al. Epidemiology and Management of Patients With Acute Coronary Syndromes in Contemporary Real-World Practice: Evolving Trends From the EYESHOT Study to the START-ANTIPLATELET Registry. Angiology. 2018;69: 795-802. https://doi.org/10.1177/0003319718760917.

22. Robinson D, Bevan E, Hinohara S, Takahashi T. Seasonal-Variation in SerumCholesterol Levels - Evidence from the Uk and Japan. Atherosclerosis. 1992; 95:15-24. https://doi.org/10.1016/0021-9150(92)90171-C.

23. Moura FA, Dutra-Rodrigues MS, Cassol AS, Parra ES, Zago VHS, Panzoldo NB, et al. Impact of Seasonality on the Prevalence of Dyslipidemia: A Large Population Study. Chronobiol Int. 2013;30:1011-5. https://doi.org/10.3109/ 07420528.2013.793698.

24. Manttari M, Javela K, Koskinen P, Pikkarainen J, Manninen V, Huttunen J, et al. Seasonal-Variation in High-Density-Lipoprotein Cholesterol. Atherosclerosis. 1993;100:257-65.

25. Zhou X, Lin H, Zhang S, Ren J, Wang Z, Zhang Y, et al. Effects of climatic factors on plasma lipid levels: A 5-year longitudinal study in a large Chinese population. J Clin Lipidol. 2016;10:1119-28. https://doi.org/10.1016/j.jacl.201 6.06.009.

26. Skutecki R, Cymes I, Draganska E, Glinska-Lewczuk K, Bucinski A, Drozdowski $M$, et al. Are the Levels of Lipid Parameters Associated with Biometeorological Conditions? Int J Environ Res Public Health. 2019;16:4636. https://doi.org/10.3390/ijerph16234636.
27. Li XX, Zhao Y, Huang LX, Xu HX, Liu XY, Yang JJ, et al. Effects of smoking and alcohol consumption on lipid profile in male adults in northwest rural China. Public Health. 2018;157:7-13. https://doi.org/10.1016/j.puhe.2018.01. 003.

28. Luo LF. The [Analysis of Consumption Behavior and Consumption Market of Our Country's Beer]. J Sanming Univ. 2009;26:41-6.

29. Mann S, Beedie C, Jimenez A. Differential Effects of Aerobic Exercise, Resistance Training and Combined Exercise Modalities on Cholesterol and the Lipid Profile: Review, Synthesis and Recommendations. Sports Med. 2014:44:211-21. https://doi.org/10.1007/s40279-013-0110-5.

\section{Publisher's Note}

Springer Nature remains neutral with regard to jurisdictional claims in published maps and institutional affiliations.
Ready to submit your research? Choose BMC and benefit from:

- fast, convenient online submission

- thorough peer review by experienced researchers in your field

- rapid publication on acceptance

- support for research data, including large and complex data types

- gold Open Access which fosters wider collaboration and increased citations

- maximum visibility for your research: over $100 \mathrm{M}$ website views per year

At BMC, research is always in progress.

Learn more biomedcentral.com/submissions 